\section{Enthusiastic but Inconsistent: Graduate Teaching Assistants' Perceptions of Their Role in the CURE Classroom}

Emma C. Goodwin, Jessica R. Cary, and Erin E. Shortlidge*

Biology Department, Portland State University, Portland, OR 97201

\begin{abstract}
Despite growing evidence of positive student outcomes from course-based undergraduate research experiences (CUREs), little consideration has been given to employing graduate teaching assistants (GTAs) as CURE instructors. GTAs may be novice researchers and/or teachers and likely vary in their interest in teaching a CURE. Guided by expectancy-value theory, we explored how GTAs' self-efficacy and values regarding teaching a CURE impact motivation and perceptions of their roles as CURE instructors. Using a multiple case study design, we interviewed nine GTAs who taught a network CURE at one research institution. Though most GTAs held a relatively high value for teaching a CURE for a range of reasons, some GTAs additionally perceived high costs associated with teaching the CURE. Through the interview data, we established three profiles to describe GTA perceptions of their role as CURE instructors: "Student Supporters," "Research Mentors," and "Content Deliverers." Those implementing GTA-led CUREs should consider that GTAs likely have different perceptions of both their role in the classroom and the associated costs of teaching a CURE. The variability in GTA perceptions of CUREs implies that undergraduate students of different GTAs are unlikely to experience the CURE equivalently.
\end{abstract}

\section{INTRODUCTION}

Evidence supporting positive impacts of student participation in course-based undergraduate research experiences (CUREs) has catalyzed efforts by universities to adopt CUREs in many introductory biology laboratory classes-a time point when research experiences may make the greatest impact in student interest in science, technology, engineering, and mathematics (STEM) (National Academies of Sciences, Engineering, and Medicine, 2015). In CUREs, undergraduates typically collaborate on research projects within the structure of a lab course, and through that research experience, they have the opportunity to make novel and relevant contributions to the scientific community (Auchincloss et al., 2014; Brownell and Kloser, 2015). Research on CUREs report positive student outcomes, including increases in self-efficacy in research skills, interest in pursuing scientific careers, and improved retention in STEM degrees (Harrison et al., 2011; Brownell et al., 2012; Rodenbusch et al., 2016). While there is evidence of student benefits from CURE participation across course contexts, the literature rarely explicitly reflects on who is teaching the CURE. At most research institutions, graduate teaching assistants (GTAs), rather than faculty, teach traditional introductory biology labs (Sundberg et al., 2005). As universities expand implementation of CUREs, many will inevitably employ GTAs as instructors, necessitating a consideration of the potential impacts of GTA-taught CUREs—-for both undergraduate students and the GTAs themselves.

Faculty instructors of CUREs have reported that the CURE environment can be very different from that of other types of courses-in both positive and negative ways. For example, faculty instructors who teach CUREs reported personal benefits such as increased enjoyment in the classroom and opportunities for furthering research
James Hewlett, Monitoring Editor Submitted Apr 28, 2021; Revised Aug 30, 2021; Accepted Sep 29, 2021

CBE Life Sci Educ December 1, 2021 20:ar66 DOI:10.1187/cbe.21-04-0106

*Address correspondence to: Erin E. Shortlidge (eshortlidge@apdx.edu).

(c) 2021 E. C. Goodwin et al. CBE-Life Sciences Education ( 2021 The American Society for Cell Biology. This article is distributed by The American Society for Cell Biology under license from the author(s). It is available to the public under an Attribution-Noncommercial-Share Alike 3.0 Unported Creative Commons License (http://creativecommons.org/licenses/ by-nc-sa/3.0).

"ASCB®" and "The American Society for Cell Biology $\circledR^{\prime}$ are registered trademarks of The American Society for Cell Biology. 
productivity (Shortlidge et al., 2017). However, faculty instructors also reported experiencing hurdles, including increased time investment in course implementation and planning, student resistance to CURE instruction, the unpredictability of scientific research, and the challenges of being a mentor rather than solely an instructor, which necessitates providing emotional and research support to students (Shortlidge et al., 2016). These hurdles warrant consideration-a successful CURE instructor does more than simply teach a traditional or inquiry lab class in which they might lead students in a set curriculum or guide students through experiments that have little potential for novel or relevant discovery (Domin, 1999; Buck et al., 2008; Brownell and Kloser, 2015). Rather, CURE instructors are expected to lead the class, help students troubleshoot unexpected research outcomes, serve as research mentors, and support their students in building competency and independence as researchers, all with the idea that students will collect novel data relevant to the scientific community. If faculty CURE instructors find this multifaceted role challenging (Shortlidge et al., 2016), it will likely also be challenging for GTAs, who are often less experienced both as researchers and as teachers.

Although it is certainly not always the case, faculty instructors may have autonomy in their decision to teach a CURE, while graduate students are likely to be placed in a teaching assignment to meet a programmatic requirement or out of necessity to receive tuition remission and/or a stipend. Multiple studies have reported that graduate students sometimes feel they lack ownership and creative license in their teaching, because unlike faculty instructors of record, they often have little control over the curricula they are expected to teach (Park, 2002; Luft et al., 2004; Goodwin et al., 2018). Despite this tension, biology graduate students largely have positive attitudes toward evidence-based teaching (Goodwin et al., 2018; Lane et al., 2019) and believe teaching to be synergistic with their research activities (Reid and Gardner, 2020). Though a minority of graduate students in each of these studies had clear negative attitudes toward teaching or perceived it as detracting from their research productivity, evidence suggests that time spent teaching does not, in fact, reduce progress in research activities (Feldon et al., 2011; Shortlidge and Eddy, 2018).

While many biology GTAs may have positive attitudes toward teaching, it is important to remember that the GTAs who do not feel enthusiastic or motivated to teach are still being placed in teaching assignments. We hypothesize that, across the board, GTAs will vary in their interest and motivation to teach a CURE, which could impact their students' experiences. This could be particularly problematic in the context of a CURE, because instructors need to scaffold five distinct components for students in a CURE: use of multiple scientific practices, collaboration, iteration, discovery, and broader relevance (Auchincloss et al., 2014). Specifically, GTAs who value teaching and who understand and agree with the philosophy and intentions of a CURE's potential to benefit students will be more likely to support their students' experiences with these essential CURE elements and to embrace their role as research mentors.

To date, few studies have explored the experiences and impacts of employing GTAs to teach CUREs. Esparza et al. (2020) report that the CURE structure prompts different teaching behaviors for GTAs: GTAs of CUREs at one institution spent more time both lecturing to their students and engaging in interactive behaviors, such as posing questions or talking to students individually, than GTAs of non-CURE laboratory courses. An exploratory study of the perceptions of 11 GTAs at a different institution found that GTAs appreciated the opportunity to gain experience serving as a research mentor in a CURE, but also were challenged by their perceived lack of expertise and preparedness to serve as a research mentor to CURE students (Heim and Holt, 2019). We do not know how a perceived lack of expertise or modified teaching methods, as necessitated by the structure of a CURE, will impact a GTA's understanding of and motivation for the role of a CURE research mentor.

Although we know little about the experiences of GTAs who mentor undergraduates in a CURE, studies have focused on graduate students who mentor undergraduates in apprentice-style research experiences. Graduate students are largely motivated to mentor undergraduate researchers because of perceived extrinsic benefits, such as the expectation that mentoring undergraduate researchers will increase their own research productivity (Dolan and Johnson, 2009; Hayward et al., 2017; Limeri et al., 2019). Early-career mentors in particular, such as graduate students, may be more likely than experienced faculty to be motivated by external factors when choosing to invest time in mentoring (Hayward et al., 2017). Further, many graduate student mentors have intrinsic value for mentoring undergraduate researchers, describing more benefits than costs (Dolan and Johnson, 2009; Limeri et al., 2019). We expect that some of these perceived benefits and costs may shift when a graduate student takes on a mentorship role in a CURE: for example, because the mentees are not contributing to work that directly advances the graduate student's dissertation research, there may be a lower expectation for extrinsic benefits.

We first explored GTAs' perceptions of their role in the CURE classroom through an interview study $(n=22$; E.C.G. and E.E.S., unpublished data). We interviewed GTAs teaching CUREs in a multitude of course contexts from universities nationwide. However, it was immediately apparent that external variables, including the varying level of responsibility and support a GTA may have in teaching the CURE and the wide diversity of structure and complexity of different CUREs, obscured our ability to isolate and compare the perspectives that individuals might hold regarding the CURE context. We learned from these pilot data and subsequently revised our approach: Here we used a multiple case study design to explore the experiences of individual GTAs teaching a CURE during a single term at one university. The case study approach allowed us to gain a deep understanding of the context in which GTAs were operating and therefore to better interpret how and why individual GTAs differ in experiences, perceptions, and attitudes regarding teaching a CURE (Yin, 2017).

\section{Theoretical Frameworks}

In this work, we consider the motivation that STEM graduate students may feel toward the task of teaching a CURE. In most cases, graduate students come to graduate school with the expectation that they will conduct research, and conferral of a degree is contingent upon production of a body of research. Many GTAs may therefore be motivated to teach at least in part because they are driven by extrinsic factors (e.g., the external reward of getting a stipend or punishment of not being able to 
afford graduate school without the tuition remission). Self-determination theory (SDT) proposes that these external motivators are less powerful than more autonomous drivers, such as intrinsic motivation (i.e., interest or enjoyment of an activity) and other internalized motivators (i.e., valuing an activity or seeing it as part of one's identity; Ryan and Deci, 2000, 2020). Indeed, many studies on student motivation, including a large metanalysis on the topic, have found these more autonomous motivators are associated with improved affective and academic outcomes, which could be due to greater motivation to invest in the activity (Ryan and Deci, 2020; Howard et al., 2021). Therefore, when we consider motivation in the context of this work, we prioritize the internalized, autonomous forms of motivation that tend to result in increased investment in an activity. For GTAs teaching CUREs, this emerges as the motivation that a GTA might feel to invest and buy into the task of providing students with a research experience via teaching a CURE, rather than an extrinsic desire to simply complete a teaching requirement necessary to stay in graduate school.

Our study design and analysis is largely guided by expectancy-value theory (EVT), which posits that the subjective value one holds for a task and one's expectancy to succeed at the task will impact one's motivation to invest effort and strive to perform well at that task (Wigfield and Eccles, 2000). Subjective task value can be broken down into four main components: attainment value, intrinsic value, utility value, and cost (Eccles and Wigfield, 2002). As summarized in Eccles and Wigfield (2002), attainment value encompasses both the personal importance of the task and the relevance of the task to one's identity, which is referred to as ideals-centered or identity-centered attainment value. Intrinsic value, as in SDT, is the interest and enjoyment one gains from the task. Utility is the value one holds because the task aligns with current and future personal goals, but also represents the tangible extrinsic values one might have for a task. For the GTAs in this study, we therefore distinguish between professional development-centered utility value (e.g., improving teaching, research, and communication skills) and tangible utility (e.g., stipend, tuition remission, or enhancing one's curriculum vitae). The final component of the subjective task value framework as defined by Eccles and Wigfield (2002) is cost, which includes both the negative emotional aspects of the task and the effort and opportunity cost of participating in the task. In this study, we therefore distinguish between emotional costs and costs related to time spent on the CURE (opportunity cost).

EVT has previously been used to explore GTAs' motivation to teach a guided-inquiry curriculum in chemistry labs through interviews with six GTAs (Wheeler et al., 2018). Three of the GTAs had high expectancy beliefs in their ability to effectively facilitate an inquiry-based course, and these individuals also had prior experience as either a student or an instructor in an inquiry classroom, suggesting that prior experiences with the course structure could contribute to expectancy for success in teaching. GTAs in the study also reported high intrinsic value and low costs associated with teaching the inquiry curriculum but did not perceive utility or attainment value (Wheeler et al., 2018). Although interest in CUREs has grown in recent years, CUREs are not a ubiquitous feature of undergraduate biology lab curricula. We therefore expect that many biology GTAs will not have experienced a CURE as students themselves and may

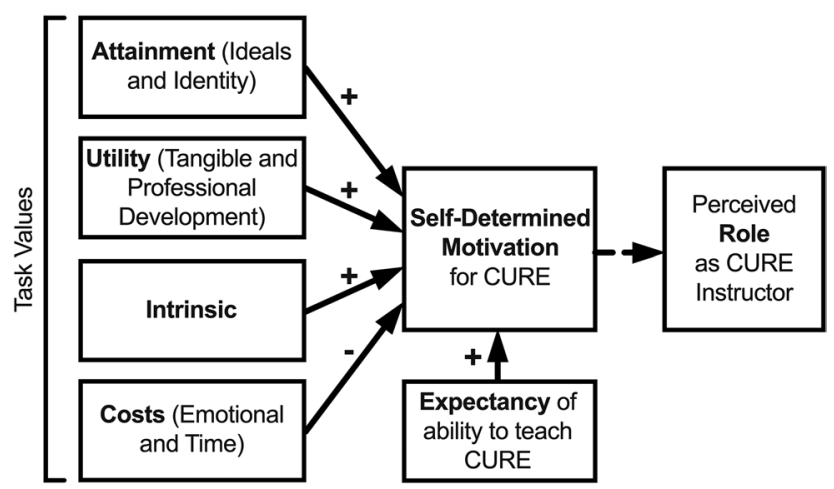

FIGURE 1. Expectancy-value model of how task values and expectancy to succeed may impact GTA autonomous motivation to invest in teaching the CURE. GTA motivation may, in turn, impact how GTAs perceive the Mentor role. Modified from Wigfield and Eccles (2000).

therefore have lower expectancy for success in teaching CUREs. GTA subjective task value may also be affected by the structural differences between inquiry and CURE models: In inquiry courses, students simulate the process of science; in CUREs, students actually participate in a research project with the potential for relevant and novel scientific discovery (Auchincloss et al., 2014; Cooper et al., 2019; Goodwin et al., 2021). However, because the intention of a CURE is to engage students in research, we expect GTAs may perceive higher utility and attainment value than GTAs in inquiry courses, as they will serve as research mentors to students in a manner that they may perceive to be more directly translatable and applicable to their own graduate research and/or future career.

\section{Research Questions}

Guided by EVT, we hypothesized that GTAs' subjective task value and expectancy for success will impact their motivation to invest effort in teaching the CURE and that this relative motivation will impact how the GTAs perceive their role and responsibilities as a CURE instructor (Figure 1). Here we explore the perceptions, attitudes, and approaches GTAs take when tasked with teaching a CURE. Specifically, we use EVT to examine GTAs' 1) task value, 2) expectancy for success, and 3) overall motivation to invest in teaching CUREs and consider what these qualities can tell us about GTA perceptions of their roles in the CURE classroom.

\section{METHODS \\ Study Context}

In 2019, we conducted a study examining a large-scale introductory biology CURE at a high research activity institution in the Pacific Northwest. We used a multiple case study design, wherein each GTA and their students collectively represented a unique "case" within the overall CURE context (Yin, 2017). This site was well suited for our study, as CUREs have been implemented in the introductory biology curriculum for several years, and this is therefore a stable and consistent system with a relatively large population of both undergraduate students and teaching assistants. Lab curriculum at this institution follows the Howard Hughes Medical Institute SEA-PHAGES 
model, which is an established and widespread network CURE model in classrooms across the United States (Jordan et al., 2014). In this institution's SEA-PHAGES CURE, students collaborate in teams of four to isolate bacteriophages from locally collected soil samples. Teams then enrich and purify their phage samples, make basic morphological characterizations, isolate genomic DNA samples, and conduct restriction enzyme analyses of the genome. Students therefore experience the CURE elements outlined by Auchincloss and colleagues (2014) by: 1) using multiple scientific laboratory techniques and practices throughout the term; 2) iterating experiments that do not work, especially during the initial phage isolation; and 3) collaborating in small groups and with course instructors to complete their research projects. Because of the enormous diversity of soil bacteriophages, the assumption is that any phages students collect are unlikely to have been previously characterized, allowing students who successfully find a phage to make a small but 4) novel scientific discovery that is recorded in an online public database. While student-isolated phages are collected and stored for potential future use by other scientists, not much is known about the bacterial host itself, and students do not have the opportunity to sequence their phages for genomic analyses, which reduces the 5) broader relevance of their research.

Throughout the semester, approximately 450 students enrolled in a single introductory biology course and were coenrolled in 20 associated lab sections taught by nine GTAs. GTAs are either assigned or, in some cases, request to teach the CURE, and most teach their lab sections with the assistance of an undergraduate TA who had previously taken the course. GTAs were supported throughout the term by the faculty instructor and lab coordinator for the course and participated in a weeklong CURE boot camp at the beginning of each term as well as weekly GTA meetings. In the boot camp, GTAs met with the faculty instructor and/or lab coordinator for 2 to 3 hours a day to discuss the purpose and intentions of conducting the CURE, receive some pedagogical training, and practice the scientific protocols that students use during the first half of the semester. During the weekly GTA meetings, GTAs met with the faculty instructor and coordinator to discuss what to expect in the upcoming week's lab and any issues they experienced while teaching and to collaboratively brainstorm ideas for improving the labs.

We recruited GTAs to participate in our study with the help of the faculty instructor and the lab coordinator. By participating in the study, GTAs agreed to take three surveys throughout the term, participate in an end-of-semester interview, allow the researchers to observe and record their classes, and facilitate our student data-collection efforts (i.e., recruiting students for surveys and allowing us to conduct in-class focus groups). GTAs were offered a \$75 gift card for participating in the study, and all nine GTAs agreed to participate. This study was approved by the Portland State University Institutional Review Board (no. 196388-18).

\section{Interview Protocol}

In this study, we explore the different perceptions and experiences of the nine GTAs, largely derived from end-of-term interviews. Interviews were conducted by a researcher (E.C.G.) who had experience teaching CUREs, including the SEA-PHAGES curriculum. At the time of the interview, the researcher had observed each GTA teaching for at least one CURE lab period and had been in contact with the GTAs regarding the study throughout the term. The researcher had therefore developed some familiarity with each GTA and the context in which they taught.

Interviews were designed to explore the different types of subjective task value each GTA might hold regarding the CURE. To encourage GTAs to reflect on the value they place on the CURE, we administered a card-sort activity during the first half of the interview. For the card sort, we (E.C.G. and E.E.S.) developed 36 statement cards, with eight to 10 statements aligning with each of the four subjective task value categories (intrinsic, attainment, utility, and cost; Supplemental Material, Appendix 1). For example, the statement "Teaching the CURE lab looks good on my CV" represents utility value, and "It is fulfilling to see students get engaged with their projects in the CURE lab" represents intrinsic value. Development of the card statements was informed by our previous work exploring the perceptions of CURE instructors, including a nationwide sample of GTAs (unpublished data) and faculty instructors (Shortlidge et al., 2016, 2017). GTAs were asked to rank the cards from -4 ("Least like your experiences and perspectives") to +4 ("Most like your experiences and perspectives") and place their cards on an outlined grid in a forced normal distribution, as in Q methodology (Watts and Stenner, 2012; for grid template, see Supplemental Material, Appendix 2). While the card-sort activity was inspired by $\mathrm{Q}$ methodology, we did not conduct a $\mathrm{Q}$ factor analysis, but rather used the activity to promote reflection and guide discussions with the GTAs.

At the start of the interview, each GTA spent 15-20 minutes reflecting on the cards and silently organizing them on the board. For the next 10 minutes of the interview, the interviewer prompted the GTA to verbalize their reflections and explain their reasoning for each of the card placements, interrupting only to ask clarifying questions about the GTA's explanations. This portion of the interview served to promote the GTA's reflection on topics relevant to our research questions, preparing GTAs to thoughtfully respond to our predetermined interview questions. These questions were delivered after the reflection activity in a semistructured format, with the interviewer asking a predetermined set of questions and following up with the GTA when needed (Cohen and Crabtree, 2006; for full interview protocol, see Supplemental Material, Appendix 3).

We piloted the interview protocol on five $\mathrm{PhD}$ students and recent $\mathrm{PhD}$ graduates who had experience as a GTA, and modified statements that caused confusion or were not interpreted as intended during the pilot interviews.

\section{Data Analysis}

Audio from interviews, including both the card-sort reflections and the semistructured questions, was transcribed and de-identified for analysis. We sequentially used provisional and holistic coding strategies to analyze interview transcripts (Saldaña, 2015). An initial provisional codebook was generated by a single researcher (E.C.G.). Like the card-sort statements, this codebook was informed by our previous work with GTA and faculty CURE instructors and was specifically designed to capture GTA beliefs and perceptions related to both the CURE constructs and EVT. Two researchers (E.C.G. and J.R.C.) then read through all GTA interview transcripts and generated new codes 
or clarified a priori codes within the CURE and EVT frameworks. Each code was a short descriptor that described an aspect of the CURE or EVT constructs and was accompanied by a longer definition to provide coders with guidance on how the code should be used. For example, within the EVT construct of utility, we included the code "Teaching the CURE offers GTA career clarification," which we used when "the GTA finds career clarification for themselves, and the experience affirms or informs their desire to have teaching be (or not be) a part of their future career." We additionally developed a few codes outside the EVT framework that we felt were valuable for interpreting the experiences of the GTAs, including codes that described the perceived role the GTA had in the classroom. Upon finalizing the codebook, both reviewers read through all interviews and independently coded each interview. The reviewers then met and discussed each code designation to consensus. Several additional iterations of coding ensued to check each code designation: One reviewer read through each code to check that coding was accurate and consistent across interviews, and both reviewers recoded the mentor role codes for each interview to ensure that the codes were used as intended across all GTAs. Finally, the reviewers reread the interviews and used the applied codes to holistically evaluate each GTA's overall value of the CURE.

As a proxy for the saliency of different task values to each GTA interviewee, we calculated the proportional frequency with which the GTA brought up each subjective task value within the interview. To do this, we summed the codes related to each specific task value and divided the sum by the total number of codes related to any of the task values in each interview. We recognize that this is an imprecise measure of saliency: The frequency at which a certain task value was discussed within the interview could be influenced by the structure and flow of the interview or the degree to which a GTA chose to elaborate on something within the conversation. Despite these limitations, we determined that the number of times each GTA referenced specific task values, when combined with the qualitative analyses of the discussion itself, provides useful insight into which task values they personally find most salient.

While considering the GTA interviews, we observed distinct patterns in the manner that GTAs spoke about their role in the CURE classroom. Therefore, after our first round of coding, we inductively developed three additional codes to capture the various styles in which GTAs described their role and purpose in the classroom. We applied the code "Student Supporter" when a GTA implied that their role, purpose, or personal goal was to provide any kind of emotional support for their students (e.g., making their students feel comfortable, happy, or supported in the classroom). "Research Mentor" was applied when a GTA described offering guidance or support to students in a manner that would allow students to develop their autonomy and independence as researchers. Finally, we applied the code "Content Deliverer" when a GTA implied that their role in the classroom is to pass knowledge on to students. GTAs often expressed strong commitment to multiple roles within the space of their interviews, which was demonstrated through the number of times the GTA discussed the role within the interview, the depth and emotion that the GTA attached to that role, and the number of different ways the GTA demonstrated commitment to the role (i.e., Student Supporters might focus on encouraging their students to persist in their projects, trying to make class time fun for students, or trying to foster students' curiosity with their research projects). We used these three codes to create profiles of each GTA's teaching style: We assigned a holistic Student Supporter designation to GTAs who, in their interviews, primarily made statements that we coded as Student Supporter, and similarly assigned Research Mentor and Content Deliverer labels to GTAs who primarily discussed embodying those roles. Some GTAs discussed Student Supporter and Research Mentor ideas without clearly prioritizing one style over the other. These GTAs were therefore assigned a joint "Student Supporter/ Research Mentor" designation.

\section{RESULTS}

\section{Participant Information}

Of our nine GTA study participants, three were pursuing master's degrees and six were pursuing PhDs. While two GTAs were teaching the CURE for the first time, the rest had one to five terms of previous experience teaching the course. On average, participants were 29.6 years old $(S D=5.2)$. Six GTAs self-identified as female, and three identified as male. Six GTAs self-identified as white, while three identified as South Asian international students. To protect the identity of our nine GTA study participants, we avoid connecting any personal participant information with our findings in this study. As the GTAs were teaching the SEA-PHAGES curriculum, we assigned GTAs seathemed pseudonyms.

\section{GTAs Have a High Expectancy for Success in Teaching the CURE}

Within the interviews, we specifically asked each GTA what additional knowledge, experiences, or training would improve their ability to teach the CURE. In response to this question, and in other places in the interviews, nearly all GTAs expressed that they generally felt very confident in their ability to teach the CURE (Table 1). For example, while reflecting on the card-sort portion of the interview, Coral explained:

\footnotetext{
I had enough content knowledge [to teach the CURE]. Sometimes it could be challenging if it was something new... but it was not difficult for me to catch up. ... I think I had enough research skill and experience to guide the students. Sometimes I needed to talk to [the faculty instructors], but most of the time I was fine... [The weekly TA meetings] prepared me for the following week, which was really helpful, especially for me, because I was teaching [for the first time]... I was always certain I could do it. I was prepared.-Coral
}

Most GTAs indicated that the key to their confidence was experience (seven GTAs); having taught the SEA-PHAGES CURE once, they had the basic ability and familiarity with the protocols to teach it again. As demonstrated in the preceding quote, many also described the strong support they had (seven GTAs), which contributed to their self-efficacy regarding teaching the CURE-the faculty instructors and other GTAs were available to answer questions, they had an undergraduate assistant in the classroom who had previously taken the course and was available to help, and they had weekly TA meetings to discuss the course. 
TABLE 1. GTAs' expectancy beliefs about their ability to teach the CURE

\begin{tabular}{|c|c|c|c|c|c|c|c|c|c|}
\hline GTA & Krill & Sand & Coral & Urchin & Wave & Shell & Puffin & Kelp & Orca \\
\hline $\begin{array}{l}\text { Feels confident and capable in teaching } \\
\text { CURE }\end{array}$ & $\sqrt{ }$ & $\sqrt{ }$ & $\sqrt{ }$ & $\sqrt{ }$ & N/A & $\sim$ & $\sqrt{ }$ & $\sqrt{ }$ & $\sqrt{ }$ \\
\hline $\begin{array}{l}\text { Indicates that more training would have } \\
\text { improved teaching }\end{array}$ & $\times$ & N/A & $x$ & $x$ & $\sqrt{ }$ & $\sqrt{ }$ & $\sqrt{ }$ & $x$ & $\times$ \\
\hline
\end{tabular}

${ }^{a} \mathrm{~A} \sqrt{ }$ indicates the GTA firmly expressed a particular sentiment; a $\sim$ indicates the GTA expressed uncertainty in their response; and an $\times$ indicates the GTA specifically stated the opposite of the sentiment (e.g., they did not feel that more training would improve their teaching). N/A indicates that the GTA did not clearly address the topic in the interview.

Only Shell, who was teaching the CURE for the first time, indicated that though they were generally confident in their teaching, they sometimes lacked confidence in teaching protocols they had never done before and would have appreciated more training in the protocols (Table 1). Two experienced GTAs noted that additional skills-based training would have been helpful before their first term in the CURE; however, they felt that such training was no longer necessary, as they had learned the protocols while teaching in previous terms. Finally, Wave and Puffin, who did not claim to lack confidence in their ability to teach the CURE, both indicated their teaching would generally improve with more formal training in evidence-based teaching practices (Table 1).

\section{GTAs Prioritize Several Types of Task Value Associated with Teaching the CURE}

We found that, throughout the interviews, all GTAs described several different types of task value that resonated with them when considering their experience and perspectives in teaching the CURE (Table 2). Eight of the nine GTAs indicated that they

\section{TABLE 2. Task value codes with example GTA interview quotes ${ }^{a}$}

Code and definition

Attainment (Ideals): GTA believes that CUREs are important

because they are valuable for the undergraduate students.

Attainment (Identity): Teaching (either the CURE or in general) is personally important to the GTA.

Intrinsic: GTA finds teaching the CURE to be rewarding, stimulating, or enjoyable.

Utility (Professional Development): GTA acknowledges benefits from teaching the CURE. Benefits include developing their communication, research, and mentoring skills or clarifying their own career goals.

Utility (Tangible): GTA acknowledges teaching the CURE is useful to them. It may pay their stipend/tuition, or it offers tangible professional benefits (looks good on a curriculum vitae, helps them get jobs, etc.)

Costs (Emotional): GTA expresses teaching the CURE has costs. It may be frustrating or emotionally exhausting, often because it is difficult to engage students or to deal with students who are frustrated with iteration/failure in the course.

Costs (Time): GTA expresses that time spent teaching the CURE is an inconvenience.

\section{GTA example quote}

"[Compared with traditional labs, CUREs] give students a better introduction to what research is like. It reinforces students' ability to acknowledge what is genuine research and what should not be considered as research .... I think it really engages students. I think it's a good teaching mechanism and I think it gives them a much more realistic expectation for future careers in this field."-Wave

"Teaching is my passion. Maybe in future I'll choose the teaching profession. [Teaching the CURE] is just part of teaching, so I'm enjoying it actually."Kelp

"It was fun. It was enjoyable. I really enjoyed teaching this class and seeing the students engaging in their projects .... I could even use the examples coming from my $\mathrm{PhD}$ research to teach them the material, which was helpful and kind of interesting for me. And compared with other TAships that I had before, I had more responsibilities, but that was not something bad. I liked it."-Coral

"When you're teaching how to do research and you're learning how to do it yourself as a grad student, the more you know, the more you can tell your students. And the more you teach it, the more you're thinking about it as well. Even if you already know it, you're further gaining expertise by teaching it."-Puffin

"Being paid in tuition is actually huge, because I wouldn't be able to even be here at school [without teaching]. I wouldn't be able to pay for [school].... I'm going to have to keep going in a $\mathrm{PhD}$, so having TA experience on my résumé can be a good thing."-Shell

"It can be difficult to get them excited when they don't get a phage. I mean the success rate is very low, and they end up writing in the reflection, 'We did everything correctly but we didn't find a phage.' Like they are trying to blame things on you [the GTA]."-Krill

"In our department, teaching isn't valued very much and it's basically just seen as a way to pay your tuition and stipend if your PI can't fund you. But you're still assessed in the same way as students who don't have to TA. I feel like it's not really taken into account like, 'Hey, I have to spend like 15 to 20 hours a week teaching,' because nobody seems to really care about that. They just care about your actual research progress."-Urchin 
A.

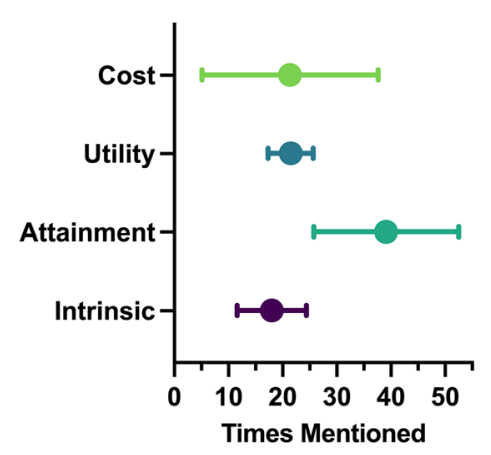

B.

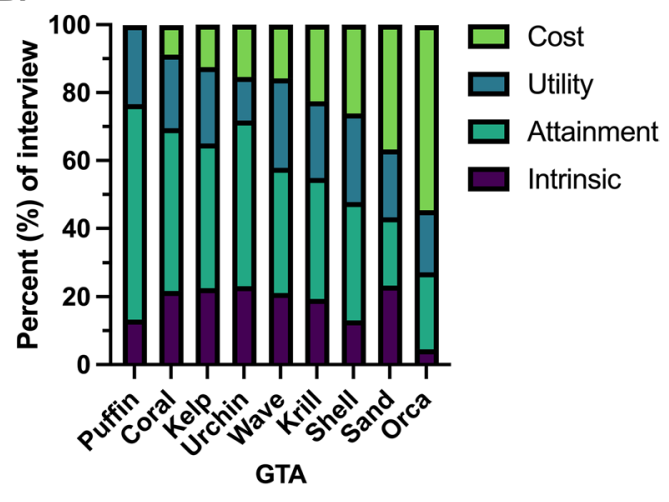

FIGURE 2. EVT task value profiles of GTAs teaching CUREs. (A) On average, GTAs most frequently discussed their attainment value for the CURE, and GTAs varied the most in how frequently they discussed attainment value and costs associated with teaching the CURE. Circles represent the mean number of times ( \pm 1 SD) each construct was mentioned in GTA interviews. (B) Individual distributions of the frequency at which each GTA discussed cost, utility, attainment, and intrinsic values for the CURE as a proportion of their entire interviews.

considered all four types of task value (attainment, intrinsic, utility, and cost) to be significant to their experience. We found that specific task values, particularly attainment and costs, were clearly more salient to some interviewees than others, which was made clear in the interviews when a GTA frequently mentioned or extensively discussed specific codes that fell within certain task value categories (Figure 2). In comparison, all GTAs expressed conceptions of utility and intrinsic value at a similar frequency (Figure 2A).

\section{Attainment Value}

Overall, the task value category that GTAs brought up the most in their interviews was attainment, or the value held for CUREs because they align with either one's ideals or identity (Table 2 and Figure 2). GTAs most frequently discussed the attainment value as it related to their ideals, or the belief that CUREs are valuable because they are particularly beneficial for undergraduate participants. GTAs specifically expressed the belief that CUREs are the "right" way to teach students (eight out of nine GTAs), that the students enjoy the CURE (eight GTAs), and that CUREs are more engaging for students (eight GTAs). GTAs also explained that CUREs are valuable to teach students resiliency (six GTAs), autonomy and ownership (five GTAs), and the process of science (five GTAs). Compared with the time spent in interviews discussing ideals-driven attainment value, GTAs focused much less on attainment value as it related to their own identities and the personal importance they held, either for teaching the CURE or teaching in general. Seven of the GTAs indicated that teaching in general was very important to them or that they took their teaching responsibilities very seriously, and four of those GTAs additionally planned to have teaching be a major part of their future careers. Just over half (five GTAs) explained that the CURE format specifically aligned with their identities as researchers, because they were able to teach students the process of research and/or make connections between their graduate work and the CURE.

\section{Intrinsic Value}

While GTAs tended to discuss their intrinsic value for the CURE less frequently on average than attainment, utility, or cost, eight of the nine GTAs found their experiences to be, at least at times, rewarding or enjoyable (Table 2 and Figure 2), as did faculty instructors of CUREs (Shortlidge et al., 2017). GTAs also described intrinsic value for the CURE in the sense that they appreciated their interactions with students (five GTAs) and their relationships with the CURE faculty instructors (four GTAs). Four GTAs described that they valued the autonomy they had in teaching the CURE and felt they had control and responsibility in the CURE that they might not have in other GTA positions.

\section{Utility Value}

All nine GTAs indicated that they perceived utility value in the CURE, particularly in the professional development skills they were able to cultivate (Table 2 and Figure 2). Specifically, GTAs described that teaching the CURE improved their teaching or mentoring skills (seven GTAs) or their research or biology skills (five GTAs). Five GTAs indicated that teaching the CURE helped develop their communication skills, and three GTAs found that their experiences with the CURE had helped inform their own career interests.

Surprisingly, given that several potential tangible benefits related to the CURE were included in our card-sort statements (see Supplemental Material, Appendix 1), only six of the GTAs discussed the tangible utility benefits from teaching the CURE, and tangible benefits were only briefly discussed when addressed at all. While many GTAs acknowledged that getting their stipend and tuition remission from teaching was, of course, important, only five of the GTAs expressed that this was one of the primary reasons why teaching the CURE was valuable to them. Five GTAs also acknowledged that teaching the CURE could provide professionally useful tangible benefits, in that it might look good on their curricula vitae or provide beneficial networking opportunities. Because previous interviews with faculty CURE instructors have revealed that faculty instructors may experience tangible benefits such as publications, recruitment of undergraduate research assistants, or professional recognition from their universities (Shortlidge et al., 2017), we intended to track when GTAs reported the same tangible benefits. However, we found that GTAs did not discuss these potential CURE benefits at all, and sometimes specifically said they did not expect to publish or that they felt their departments specifically did not value their work as a GTA (coded as Emotional Costs, two GTAs).

\section{Cost}

Though eight of the nine GTAs discussed personal costs associated with teaching the CURE, GTAs varied the most in the number of times they referenced this theme, indicating that costs associated with the CURE are likely salient for some GTAs and not a substantial issue for others (Table 2 and Figure 2). 
TABLE 3. GTA perceptions of the value of teaching a CURE

\begin{tabular}{|c|c|c|c|c|c|c|c|c|c|}
\hline GTA & Krill & Sand & Coral & Urchin & Wave & Shell & Puffin & Kelp & Orca \\
\hline Sees value in CURE for students & $\sqrt{ }$ & $\sqrt{ }$ & $\sqrt{ }$ & $\sqrt{ }$ & $\sqrt{ }$ & $\sim$ & $\sqrt{ }$ & $\sqrt{ }$ & $\sqrt{ }$ \\
\hline Sees value in CURE for GTAs & $\sqrt{ }$ & $\sqrt{ }$ & $\sqrt{ }$ & $x$ & $x$ & $\sqrt{ }$ & $\sqrt{ }$ & $\sqrt{ }$ & $\times$ \\
\hline
\end{tabular}

${ }^{\mathrm{a} A} \sqrt{ }$ indicates an affirmative agreement or belief from the GTA described in the interview how they or their students benefited from the CURE; a indicates the GTA expressed uncertainty in their position; and an $\times$ indicates the GTA stated they thought the CURE lacked value for the students/themselves.

Specifically, these eight GTAs all discussed the emotional costs of the CURE: that teaching the CURE could be frustrating or exhausting, because it can be difficult to get their students engaged and excited to participate in the CURE. Some GTAs also found it challenging to deal with students who were frustrated by experiences of iteration or failure in the CURE (four GTAs). Finally, seven GTAs discussed that a major cost of teaching the CURE was time spent away from research, though GTAs spent little time in their interviews discussing this point.

\section{Perceived Value Impacts GTAs' Motivation and Enthusiasm for Teaching the CURE}

When considering each GTA's interview holistically, it was apparent that most GTAs were enthusiastic about the CURE pedagogy, which they expressed through their repeated emphasis of the value they see in the CURE experience either for their students and/or for themselves. Ultimately, seven of the nine GTAs felt that CUREs were overall a highly beneficial experience for introductory students, while Orca alone decisively felt that research-based courses were not worthwhile for students at an introductory level (Table 3). While Shell felt the CURE was very engaging for students, they too ultimately doubted the utility value for students:

I don't know whether [this type of research] is something [students] can really put on their résumé, so I don't know how much it really benefits them.--Shell

While most GTAs felt that teaching the CURE was a net positive and valuable experience for GTAs as well as for their students, Urchin, Wave, and Orca expressed that teaching the CURE was not necessarily advantageous for GTAs (Table 3). For example, while Wave thought CUREs were good for their students and recognized many professional development opportunities within a CURE, they ultimately felt that time spent teaching was a net negative for GTAs, as demonstrated by this quote:

\footnotetext{
I don't think TAing is a massive résumé builder.... TA experience can help [build your résumé], but it also comes at the cost of having less research experience ... Probably more than one semester of TAing isn't going to help your CV that much. And I do not feel like teaching [the CURE] contributes to my research. I'd actually say that it really detracts from my research in a lot of different ways as my time is directed more toward teaching and learning how to teach than it is to getting my papers published and my research done.-Wave
}

We directly asked GTAs if they would use a CURE model if they were designing their own introductory biology lab class, and most GTAs affirmed that they would (Table 3). Only Sand and Orca expressed reservations about the CURE model, primarily because they felt that an introductory biology class should prioritize reinforcing concepts taught in the lecture associated with the lab course. Notably, Sand and Orca perceived more costs and less ideals-based attainment value associated with the CURE than any other GTAs in our study (Figure 2), indicating that they feel that the potential benefits of implementing a CURE may not outweigh the costs.

\section{Graduate Students See Themselves as Research Mentors, Student Supporters, and/or Content Deliverers}

We expected that GTAs who perceive that the CURE is ultimately a valuable experience-either for students or themselves-will be more likely to embrace their role in serving as CURE mentors in the classroom. We therefore were curious about how GTAs perceived their role in the CURE classroom, and how those perceptions aligned with their motivation to engage in teaching the CURE. We found that we could categorize the manner in which graduate students describe their role in the CURE classroom as either a Research Mentor, with the goal to build their students' autonomy and independence as a researcher; a Student Supporter, with the goal to support their students emotionally (e.g., happiness, comfort, engagement, or confidence); or a Content Deliverer, with the goal to pass knowledge on to students (Figure 3). In the following sections, we explore profiles of GTAs with varying conceptions of their role as a CURE GTA.

\section{Balancing Roles as a Student Supporter and Research Mentor: "Don't Get Scared If You Fail."}

Nearly half of the GTAs (Krill, Sand, Coral, and Urchin) considered their roles as both a Student Supporter and Research

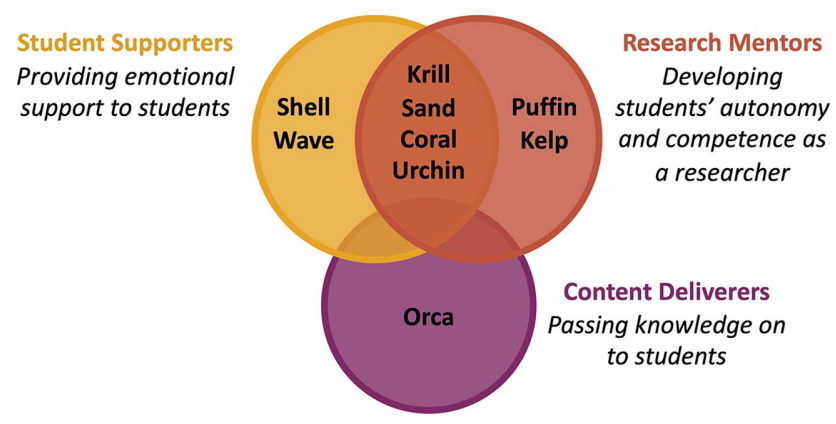

FIGURE 3. GTA roles in the CURE classroom. GTAs vary in the manner in which they appear to prioritize these different perceived roles when acting as a CURE mentor. Through holistic analysis of interviews, we placed GTAs into either distinct role categories (Student Supporter, Research Mentor, or Content Deliverer) or into the combined category of Student Supporter/Research Mentor. 
Mentor to be important in the CURE classroom (Figure 3). Because faculty CURE instructors report that CURE instruction results in an "expanded" instructor role, where instructors need to provide both emotional and research support to students (Shortlidge et al., 2016), we posit that GTAs in this group may have an advantageous conception of their instructional role. These GTAs often demonstrated their commitment to developing their students as researchers while providing emotional support by trying to increase morale and normalize failure and iteration in the research process, as demonstrated by Krill:

The first time they don't get phage, [I tell them] "Research is 99\% troubleshooting," and I give them my example: "I've been working [on part of my research] for six months and I ended up getting nothing, but I'm still here teaching and smiling, so you guys should not be sad."-Krill

Krill, Coral, and Urchin all had high ideals-centered attainment value for the CURE, indicating that they valued the CURE because they held the strong belief that it is beneficial for their students. Their belief in the value of the CURE for undergraduates perhaps motivated their commitment to their dual roles as Research Mentors and Student Supporters, as they felt that the CURE offered an opportunity for students to develop many of the affective qualities that would make them stronger researchers and students:

[The most important thing undergraduates learn in the CURE is] being independent and learning to make decisions, and to take the responsibility of those decisions ... And to teach them to have self-confidence, and to not get scared if they fail or if something goes wrong ... You have to have a plan B.-Coral

Krill articulated a sometimes-conflicting desire to satisfy their students' frustration in the CURE while also serving as a research mentor in the classroom:

Sometimes I wish I could give them the phage. Make their life easy ... But then I say, "No, that's their research, and I'll let them figure it out."-Krill

We found it notable that, although these four GTAs struck a balance of their Research Mentor and Students Supporter roles in the classroom, Krill was the only one who specifically indicated they intended to have teaching be a prominent part of their future career. Further, Sand and Urchin both emphasized they have no intention of pursuing a career in teaching and expressed reservations about the overall value of the CURE. Urchin in particular perceived much lower professional utility in teaching the CURE and discussed the time costs associated with teaching the CURE more than any other GTA. Sand experienced much higher emotional costs while teaching the CURE, mostly connected to a perceived lack of student interest and engagement:

Especially when I first started teaching this course, I got so emotionally invested in my students' performance and understanding and them caring [about the CURE], so this semester, I've taken the philosophy that you can't make someone care.
You just have to be there to support the people that do care, and then encourage those that don't.-Sand

Despite these costs and lower perceived value for the CURE, both Urchin and Sand demonstrated that they took their instructional role in the classroom seriously and were committed to acting as both a Student Supporter and a Research Mentor.

\section{Student Supporters: "Good Job, Keep It Up."}

Wave and Shell expressed strong commitment to their roles as Student Supporters, rather than Research Mentors, in the CURE classroom (Figure 3). Though Shell expressed a strong teaching identity and passion about teaching, they had little previous research experience and did not express much of a research identity themselves. This perhaps explains why they did not prioritize fostering a research identity in their students, but rather focused on engaging and encouraging students:

[One of my most meaningful responsibilities is to provide students] encouragement to do a good job, to get their work done ... A lot of them get in this mindset of "This is boring, and I don't like this." That's your attitude, it doesn't have to be boring.... [Some days there is] not necessarily a lot for me to do except watch: "Good job. Keep it up. You're following those protocols well."-Shell

Shell's dedication to engaging students perhaps explains why they experienced high emotional costs in the CURE, as they found their students' lack of enthusiasm about the CURE particularly frustrating and exhausting. However, Shell also found the CURE to provide more tangible utility than other GTAs: While other GTAs felt that their experience teaching CUREs would not matter much to future employers, Shell's limited previous research experiences meant that the CURE was consequently an important addition to their curriculum vitae in terms of demonstrating their research skills and experience.

Like Shell, Wave made it clear that they were passionate about teaching. Though Wave enjoyed the CURE and believed in the importance of evidence-based teaching and a researchbased curriculum, they struggled with the time commitment and felt it detracted from their graduate research. While those in the Research Mentor role prioritized fostering student research skills and autonomy, Wave prioritized building student engagement and curiosity toward research, especially at the introductory level:

The best I can do as a teacher is just try to engage them and try to drive that curiosity that encourages them to investigate a topic further ... Introductory classes [like the CURE] are where you teach them how to learn, and later classes are when you actually help them develop their critical thinking skills to apply new information.-Wave

Research Mentors: "You [Students] Are the Researcher." Like the GTAs who balanced their roles as Research Mentors and Student Supporters in trying to reduce student frustration with iteration and failure by normalizing these aspects of research, Puffin and Kelp emphasized the importance of iteration and failure with their students as they prioritized building student 
research skills and autonomy (Figure 3). However, unlike the Research Mentors/Student Supporters, they emphasized these aspects of research without indicating that boosting student morale or supporting student confidence was a priority for them:

[I tell them] You are the researcher. You need to be patient. Everything in the lab, it doesn't come at once. You need to repeat it.-Kelp

Though they did not discuss efforts to support their students emotionally in the course, they both clearly were passionate about teaching and cared about their students' success. Puffin explained:

My most meaningful responsibility ... [is to give my students] tools that are going to help them be successful in other courses or in their future career.-Puffin

Both Puffin and Kelp planned to have teaching be a significant portion of their careers, and more than other TAs they focused on how teaching the CURE aligned with their personal and professional values regarding teaching and research (identity-centered attainment value). Puffin especially expressed a strong interest in improving their own ability to incorporate evidence-based teaching strategies into their classroom and recognized the professional development opportunities (utility value) with teaching the CURE.

\section{Content Deliverer: "My Responsibility Is to Give the Best Knowledge to the Students."}

Orca stood out from the other GTAs in that they did not embrace either the Research Mentor or Student Supporter roles, but rather focused on transmitting instructions and knowledge to their students (Figure 3):

[I told my students,] "Your priority is to follow me, follow instructions, do research, and write."... But most students are just naïve. They are just starting in this field.-Orca

As demonstrated by this quote, Orca frequently spoke about their students with some condescension, and overall expressed less value for the CURE than other GTAs (Table 3). Within their interview, Orca focused less than the other GTAs on the benefits undergraduates received from the CURE (ideals-centered attainment value) and had the lowest intrinsic value and value for the professional development opportunities the CURE offered GTAs. Orca was the only GTA who expressed a strong preference for traditional "cookbook" labs to CUREs, at least at the introductory biology level:

Some students [in the CURE] don't understand what is going on. They start to believe that I'm not good at teaching: "[Orca's] not aware of what [they are] doing ..." So maybe they have less appreciation for my effort [in a CURE]. But when it's a cookbook course, everything's prepared, and I know [what to expect] ... The cookbook is more enjoyable for me... When [the students] get the results that I expect, I'm ready to elaborate and build on what they have seen in the test-tube or the DNA extraction... [In the cookbook labs,] I'm ready for everything.-Orca
Orca spent more time than any other GTA discussing the costs associated with the CURE and particularly highlighted experiencing high emotional costs (Figure 2). This in part was a product of their frustration with the lack of engagement and appreciation they received from their students and the uncertainty involved in teaching a CURE compared with a more traditional course (as portrayed in the preceding quote). Orca, who had previous experience teaching as an instructor of record, also felt frustration with the perceived lack of control they had over the curriculum, as Orca was expected to follow the faculty instructor's vision for how the CURE should be taught, rather than teach in the way that suited them.

\section{DISCUSSION}

We conducted this exploratory study to understand the experiences and perceptions of GTAs within a single CURE context, asking: What influences GTAs' motivation to engage in teaching the CURE, and how do they perceive their role as a CURE mentor? It is clear from our work that the experiences of GTAs are likely very different from the experiences of faculty CURE instructors. For example, GTAs in our study did not perceive a lot of tangible utility value in a CURE beyond the financial incentive and the addition of the experience to their résumés. In contrast, faculty instructors of CUREs report experiencing benefits such as the possibility of publication, recruitment of undergraduate researchers into their research labs, and professional recognition from their departments (Shortlidge et al., 2017). When prompted about these potential benefits during the cardsort portion of the interview, GTAs often specifically emphasized that they did not experience these outcomes-they had no expectation of publications resulting from their work in the CURE, and Urchin and Orca in particular reported feeling a specific lack of recognition and appreciation for their work as CURE instructors from their departments and/or students. The absence of these perceived tangible benefits is not surprising, given that the CURE did not relate to the GTAs' own research interests and the GTAs were not involved in developing the CURE: faculty instructors who implemented network CUREs (such as SEA-PHAGES) unrelated to their own research interests were also less likely to experience tangible benefits compared with faculty who developed their own independent CUREs (Shortlidge et al., 2017). These different perspectives of faculty and GTA instructors of CUREs likely translate into different approaches when teaching the CURE: previous research has found that undergraduate students perceive GTA and faculty instructors differently, in that GTAs are thought to have less expertise and confidence but may be more laid-back and relatable than faculty instructors (Kendall and Schussler, 2012). It is therefore critical to consider the impacts of GTA-taught CUREs from the perspectives of students and to further examine the instructional contexts in which CUREs appear to be effective as a teaching strategy for introductory biology labs.

EVT predicts that individuals with high value and high expectations for success at a task will experience increased motivation to engage in that task (Wigfield and Eccles, 2000; Figure 1). When applying this theory to the motivation a GTA might have for teaching a CURE, we first considered each GTA's expectations for success, or self-efficacy in teaching the CURE. As seen in previous studies on GTA self-efficacy in teaching, GTAs in our study were, overall, quite confident in 
their ability to teach a CURE (Prieto and Altmaier, 1994; DeChenne et al., 2015; Table 1). In discussing their expectations for success regarding teaching the CURE, many expressed the opinion that their hands-on experience in teaching the CURE curriculum once was sufficient to build their strong self-efficacy in teaching the CURE. GTAs also emphasized that they felt confident in their abilities to teach the CURE, because they had extensive training and support from faculty members, undergraduate assistants who had taken the course, and other experienced GTAs. These findings mirror previous studies suggesting that GTA self-efficacy is correlated with previous teaching experience (Prieto and Altmaier, 1994) and an environment that supports their teaching (DeChenne et al., 2015). Faculty instructors of CUREs echo that a supportive institutional environment is critical to successfully teaching CUREs (Shortlidge et al., 2016). We therefore expect that GTAs of CUREs who have less experience or support may therefore not experience the same high degree of self-efficacy as the GTAs in our study. While we expect this strong self-efficacy among the study participants to support their motivation to teach the CURE, recent work has found that GTA assessments of their own self-efficacy do not significantly correlate with student evaluations of their GTAs (Smith and Delgado, 2021), indicating that students have differing perceptions of their GTAs' efficacy in the classroom.

Contrary to previous work using EVT to examine GTA motivation to teach chemistry inquiry courses, which found that GTAs only described intrinsic value regarding their inquiry teaching (Wheeler et al., 2018), we found that GTAs simultaneously endorsed a wide variety of task value-related beliefs, including multiple dimensions of attainment, intrinsic, utility, and cost value (Figure 2). The differences in our findings could have been due to our methodological approach-our interview card-sort activity prompted GTAs to consider these different types of values-but it also is logical that GTAs would perceive differences in the value of teaching an inquiry course compared with a CURE. For example, the ideals-driven attainment value and emotional costs reported by GTAs of the CURE were often specifically linked to the experience of engaging students in research activities and dealing with student frustration of experimental iteration and failure-which GTAs may be less likely to experience in an inquiry course.

GTAs varied in their tendency to discuss attainment value or costs, such that GTAs who frequently discussed attainment value spent less time discussing costs, and vice versa (Figure 2). Collectively, GTAs only slightly differed in the number of times they highlighted the intrinsic and utility values associated with teaching the CURE within their interviews, and on average, GTAs discussed intrinsic value least frequently (Figure 2). Though we expected that GTAs might perceive less extrinsic or utility value than reported for graduate mentors in traditional research settings, we found GTA attitudes overall to be similar to reported attitudes that GTAs have toward mentorship in traditional research settings (Dolan and Johnson, 2009; Hayward et al., 2017; Limeri et al., 2019). Though GTAs in our study perceived the extrinsic/utility value of mentoring in a CURE to lack potential benefits of traditional research mentorships, such as an increase in research productivity, GTAs of CUREs likely recognize different types of utility value in teaching the CURE, such as professional development.
Ultimately, most GTAs recognized high value in teaching using a CURE model (Table 3). While some GTAs had more reservations about the CURE than others, only one GTA (Orca) firmly did not see value for students and indicated that the costs associated with the CURE outweighed the value. We expected that GTAs who perceived high value for the CURE would be motivated to embrace their role as CURE mentors and predicted that this motivation might impact how GTAs described their role in the classroom. Students have reported the positive impacts of instructors who provide both relational and pedagogical supports (Schussler et al., 2021), and faculty CURE instructors describe a need to provide both emotional and research support (Shortlidge et al., 2016). We therefore suggest that, ideally, a CURE GTA should strike a balance between the Student Supporter and Research Mentor roles, to support their students emotionally while developing their autonomy as student researchers (Figure 3). As expected, we found that the single GTA who expressed decisively low value for the CURE did not appear to express much commitment to either the Student Supporter or Research Mentor roles, and rather saw their role being a Content Deliverer-a role that aligns more with traditional cookbook-style laboratories, rather than a CURE. However, when we consider the other eight GTAs who had less extreme negative perceptions of the CURE, we found that strong commitment to balancing the Student Supporter and Research Mentor roles did not correspond to experiencing particularly high value and low cost for the CURE (Figures 2 and 3 ). Our findings corroborate those of a previous case study of eight GTAs in suggesting that, even within a single course context where GTAs are receiving identical training and institutional support, GTA perspectives of teaching can be quite variable, and individual perspectives may not correlate with GTA teaching practices (Addy and Blanchard, 2010).

Previous studies have found that GTAs can be hesitant to facilitate inquiry-style learning in their teaching, often gravitating toward traditional content delivery-style teaching, even in inquiry-based courses (Kurdziel et al., 2003; Gormally et al., 2016). However, the eight GTAs who perceived at least moderate value for the CURE did not strongly endorse a Content Deliverer role in the classroom-we believe this is positive, as it indicates that these GTAs were not embracing a role antithetical to the ideals of a CURE. At the same time, these GTAs did not unanimously commit to balancing the Student Supporter and Research Mentor roles, despite all having received the same training and support throughout the CURE (Figure 3). This highlights the importance of individual GTA characteristics in proposed models of GTA professional development with regard to teaching, such as the model proposed by Reeves et al. (2016). We predicted that high perceived value and low costs for teaching the CURE would promote self-determined motivation to teach, which could impact GTAs' perceptions of their role as an instructor (Figure 1). While in some cases, high perceived costs and low value for a CURE may be a warning sign that a GTA could be unprepared to balance the roles of a Student Supporter and Research Mentor in a CURE (i.e., Orca), even GTAs who seemed to have relatively high value for the CURE and aimed to balance both their Research Mentor and Student Supporter roles (i.e., Krill and Sand), perceived significant costs. Faculty coordinating CUREs should not assume that GTA characteristics such as career aspirations or apparent enthusiasm for teaching 
the CURE predicts an accurate or consistent interpretation of the GTA instructor's role in the CURE classroom. However, faculty who are training or supporting GTAs of CUREs should consider how to mitigate costs or at least prepare GTAs to handle the potential emotional and time costs that may accompany investing effort into teaching a CURE.

\section{Limitations}

We used a case study research design to gain an in-depth understanding of the experiences of GTAs in a CURE. To accomplish this, we limited our data collection to a single institution and course context and conducted detailed interviews with the nine GTAs involved with the course. Thus, our results will not be representative of GTAs at large. The experiences of GTAs teaching CUREs will inevitably be context dependent, and will vary depending on a multitude of factors, such as the training offered to GTAs, in-class support, type of CURE, and the structure of the course. GTAs in this study taught the SEA-PHAGES curriculum, which is a highly structured network CURE in which students at institutions nationwide replicate similar experimental processes with the end goal of expanding an online bacteriophage database (Jordan et al., 2014). The standardization and structure of this network curriculum could present unique advantages and disadvantages to both instructors and students, and the impacts that specific design elements of this curriculum may have on instructors and students should be further explored.

GTAs of CUREs who are offered less training or in-class support than those in this study could have lower self-efficacy or higher perceived costs, and variables such as GTA training, CURE type, and institutional culture could impact GTAs' value and understanding of their role in the CURE classroom. The experiences of GTAs in the context of our study are unlikely to translate directly to other contexts, but rather serve as an example of the possible values and role-related perceptions GTAs may have in a CURE and demonstrate the variability of GTA experiences and perceptions even within a single course context.

Within the interviews, some GTAs clearly felt more strongly about certain costs and values related to teaching a CURE than others, and individuals differed in the frequency with which they returned to certain ideas within the interview. We used the number of times a GTA brought up each of the EVT task values as a proxy for how salient that task value was for the GTA, but this is a far from perfect measure of true saliency: GTAs may have returned to certain ideas within the interview because the natural flow of the conversation prompted them to do so, or they could have been influenced by recent experiences that happened to come to mind during the interview. Though we found it useful to quantify the number of times a GTA discussed each EVT task value within their interview, we intend for these numbers to be used as an approximation rather than a precise measure of the saliency of each task value for GTAs.

Finally, we attempted to create a space for GTAs to be comfortable expressing their true perspectives and attitudes by coming in as external researchers unaffiliated with our participants' university, departments, or other social networks. We emphasized to GTAs that their responses would not be shared with the instructors of the course, and any information GTAs provided would be deidentified. Despite these precautions, and the diversity of GTA perspectives captured, GTAs were aware of the purpose and intentions of the research study, and this knowledge could have incited social desirability bias, potentially impacting the positions GTAs expressed during interviews (Grimm, 2010).

\section{CONCLUSIONS}

Our work is among the first to report on the experiences and beliefs of GTAs who teach CUREs. Those implementing GTAled CUREs should consider that GTAs likely have different perceptions of the value and costs associated with teaching a CURE both among themselves and as compared with faculty instructors of CUREs. While GTAs may value the experience of teaching a CURE, they may also have unique perspectives of their role in the classroom. We encourage faculty instructors and coordinators of GTA-led CUREs to consider that GTAs may need increased support in developing their role as a CURE mentor.

Variable beliefs and attitudes held by GTAs of CUREs could indicate that students of different GTAs are unlikely to experience the CURE equivalently. Further research can explore how student's experiences in a CURE are influenced by their individual GTAs, and if GTAs with variable perceptions of their role in a CURE are able to provide students with the "ideal" CURE experience.

\section{ACKNOWLEDGMENTS}

Thank you to the graduate student participants who generously shared their experiences and perspectives with us for this work. This work would not be possible without the substantial assistance from the faculty instructor and the lab coordinator associated with the CURE, who were critical in facilitating our on-site case studies. Thank you to two anonymous reviewers whose feedback helped to improve this work. This work was supported by a Faculty Enhancement Award to E.E.S. (20192021, PSU) and the National Science Foundation Graduate Research Fellowship Program (E.C.G.; Fellow ID no. 2018265867). Any opinions, findings, and conclusions or recommendations expressed in this material are those of the author(s) and do not necessarily reflect the views of the National Science Foundation.

\section{REFERENCES}

Addy, T. M., \& Blanchard, M. R. (2010). The problem with reform from the bottom up: Instructional practises and teacher beliefs of graduate teaching assistants following a reform-minded university teacher certificate programme. International Journal of Science Education, 32(8), 10451071. https://doi.org/10.1080/09500690902948060

Auchincloss, L. C., Laursen, S. L., Branchaw, J. L., Eagan, K., Graham, M., Hanauer, D. I., ... \& Dolan, E. L. (2014). Assessment of course-based undergraduate research experiences: A meeting report. CBE-Life Sciences Education, 13(1), 29-40. https://doi.org/10.1187/cbe.14-01-0004

Brownell, S. E., \& Kloser, M. J. (2015). Toward a conceptual framework for measuring the effectiveness of course-based undergraduate research experiences in undergraduate biology. Studies in Higher Education 40(3), 525-544. https://doi.org/10.1080/03075079.2015.1004234

Brownell, S. E., Kloser, M. J., Fukami, T., \& Shavelson, R. (2012). Undergraduate biology lab courses: Comparing the impact of traditionally based "cookbook" and authentic research-based courses on student lab experiences. Journal of College Science Teaching, 41(4), 36.

Buck, L. B., Bretz, S. L., \& Towns, M. H. (2008). Characterizing the level of inquiry in the undergraduate laboratory. Journal of College Science Teaching, 38(1), 52-58 
Cohen, D., \& Crabtree, B. (2006). Qualitative research guidelines project. Retrieved July 31, 2019, from www.qulres.org

Cooper, K. M., Blattman, J. N., Hendrix, T., \& Brownell, S. E. (2019). The impact of broadly relevant novel discoveries on student project ownership in a traditional lab course turned CURE. CBE-Life Sciences Education, 18(4), ar57. https://doi.org/10.1187/cbe.19-06-0113

DeChenne, S. E., Koziol, N., Needham, M., \& Enochs, L. (2015). Modeling sources of teaching self-efficacy for science, technology, engineering, and mathematics graduate teaching assistants. CBE-Life Sciences Education, 14(3), ar32. https://doi.org/10.1187/cbe.14-09-0153

Dolan, E., \& Johnson, D. (2009). Toward a holistic view of undergraduate research experiences: an exploratory study of impact on graduate/postdoctoral mentors. Journal of Science Education and Technology, 18(6), 487. https://doi.org/10.1007/s10956-009-9165-3

Domin, D. S. (1999). A review of laboratory instruction styles. Journal of Chemical Education, 76(4), 543. https://doi.org/10.1021/ed076p543

Eccles, J. S., \& Wigfield, A. (2002). Motivational beliefs, values, and goals. Annual Review of Psychology, 53(1), 109-132. https://doi.org/10.1146/ annurev.psych.53.100901.135153

Esparza, D., Wagler, A. E., \& Olimpo, J. T. (2020). Characterization of instructor and student behaviors in CURE and non-CURE learning environments: Impacts on student motivation, science identity development, and perceptions of the laboratory experience. CBE-Life Sciences Education, 19(1), ar10. https://doi.org/10.1187/cbe.19-04-0082

Feldon, D. F., Peugh, J., Timmerman, B. E., Maher, M. A., Hurst, M., Strickland, D., ... \& Stiegelmeyer, C. (2011). Graduate students' teaching experiences improve their methodological research skills. Science, 333(6045), 10371039. https://doi.org/10.1126/science.1204109

Goodwin, E. C., Anokhin, V., Gray, M. J., Zajic, D. E., Podrabsky, J. E., \& Shortlidge, E. E. (2021). Is this science? Students' experiences of failure make a research-based course feel authentic. CBE-Life Sciences Education, 20(1), ar10. https://doi.org/10.1187/cbe.20-07-0149

Goodwin, E. C., Cao, J. N., Fletcher, M., Flaiban, J. L., \& Shortlidge, E. E. (2018). Catching the wave: Are biology graduate students on board with evidence-based teaching? CBE-Life Sciences Education, 17(3), ar43.

Gormally, C., Sullivan, C. S., \& Szeinbaum, N. (2016). Uncovering barriers to teaching assistants (TAs) implementing inquiry teaching: Inconsistent facilitation techniques, student resistance, and reluctance to share control over learning with students. Journal of Microbiology \& Biology Education, 17(2), 215.

Grimm, P. (2010). Social desirability bias. In Wiley international encyclopedia of marketing. Retrieved August 27, 2021, from https://onlinelibrary.wiley .com/doi/abs/10.1002/9781444316568.wiem02057

Harrison, M., Dunbar, D., Ratmansky, L., Boyd, K., \& Lopatto, D. (2011). Classroom-based science research at the introductory level: Changes in career choices and attitude. CBE-Life Sciences Education, 10(3), 279286. https://doi.org/10.1187/cbe.10-12-0151

Hayward, C. N., Laursen, S. L., \& Thiry, H. (2017). Why work with undergraduate researchers? Differences in research advisors' motivations and outcomes by career stage. CBE-Life Sciences Education, 16(1), ar13. https:// doi.org/10.1187/cbe.16-07-0229

Heim, A. B., \& Holt, E. A. (2019). Benefits and challenges of instructing introductory biology course-based undergraduate research experiences (CUREs) as perceived by graduate teaching assistants. CBE-Life Sciences Education, 18(3), ar43. https://doi.org/10.1187/cbe.18-09-0193

Howard, J. L., Bureau, J., Guay, F., Chong, J. X. Y., \& Ryan, R. M. (2021). Student motivation and associated outcomes: A meta-analysis from self-determination theory. Perspectives on Psychological Science (inpress). 1745691620966789. https://doi.org/10.1177/1745691620966789

Jordan, T. C., Burnett, S. H., Carson, S., Caruso, S. M., Clase, K., DeJong, R. J., ... \& Hatfull, G. F. (2014). A broadly implementable research course in phage discovery and genomics for first-year undergraduate students. MBio, 5(1). https://doi.org/10.1128/mBio.01051-13

Kendall, K. D., \& Schussler, E. E. (2012). Does instructor type matter? Undergraduate student perception of graduate teaching assistants and professors. CBE-Life Sciences Education, 11(2), 187-199. https://doi. org/10.1187/cbe.11-10-0091

Kurdziel, J. P., Turner, J. A., Luft, J. A., \& Roehrig, G. H. (2003). Graduate teaching assistants and inquiry-based instruction: Implications for graduate teaching assistant training. Journal of Chemical Education, 80(10), 1206. https://doi.org/10.1021/ed080p1206

Lane, A. K., Hardison, C., Simon, A., \& Andrews, T. C. (2019). A model of the factors influencing teaching identity among life sciences doctoral students. Journal of Research in Science Teaching, 56(2), 141-162. https:// doi.org/10.1002/tea.21473

Limeri, L. B., Asif, M. Z., \& Dolan, E. L. (2019). Volunteered or voluntold? The motivations and perceived outcomes of graduate and postdoctoral mentors of undergraduate researchers. CBE-Life Sciences Education, 18(2), ar13. https://doi.org/10.1187/cbe.18-10-0219

Luft, J. A., Kurdziel, J. P., Roehrig, G. H., \& Turner, J. (2004). Growing a garden without water: Graduate teaching assistants in introductory science laboratories at a doctoral/research university. Journal of Research in Science Teaching, 41(3), 211-233. https://doi.org/10.1002/tea.20004

National Academies of Sciences, Engineering, \& Medicine. (2015). Integrating discovery-based research into the undergraduate curriculum: Report of a convocation. Washington, DC: National Academies Press. https://do i.org/10.17226/21851

Park, C. (2002). Neither fish nor fowl? The perceived benefits and problems of using graduate teaching assistants (GTAs) to teach undergraduate students. Higher Education Review, 35(1), 50-62.

Prieto, L. R., \& Altmaier, E. M. (1994). The relationship of prior training and previous teaching experience to self-efficacy among graduate teaching assistants. Research in Higher Education, 35(4), 481-497.

Reeves, T. D., Marbach-Ad, G., Miller, K. R., Ridgway, J., Gardner, G. E., Schussler, E. E., \& Wischusen, E. W. (2016). A conceptual framework for graduate teaching assistant professional development evaluation and research. CBE-Life Sciences Education, 15(2), es2. https://doi.org/10.1187/cbe .15-10-0225

Reid, J. W., \& Gardner, G. E. (2020). Navigating tensions of research and teaching: biology graduate students' perceptions of the research-teaching nexus within ecological contexts. CBE-Life Sciences Education 19(3), ar25. https://doi.org/10.1187/cbe.19-11-0218

Rodenbusch, S. E., Hernandez, P. R., Simmons, S. L., \& Dolan, E. L. (2016) Early engagement in course-based research increases graduation rates and completion of science, engineering, and mathematics degrees. CBE-Life Sciences Education, 15(2), ar20. https://doi.org/10.1187/ cbe.16-03-0117

Ryan, R. M., \& Deci, E. L. (2000). Self-determination theory and the facilitation of intrinsic motivation, social development, and well-being. American Psychologist, 55(1), 68-78.

Ryan, R. M., \& Deci, E. L. (2020). Intrinsic and extrinsic motivation from a self-determination theory perspective: Definitions, theory, practices, and future directions. Contemporary Educational Psychology, 61, 101860. https://doi.org/10.1016/j.cedpsych.2020.101860

Saldaña, J. (2015). The coding manual for qualitative researchers. Thousand Oaks, CA: Sage.

Schussler, E. E., Weatherton, M., Chen Musgrove, M. M., Brigati, J. R., \& England, B. J. (2021). Student perceptions of instructor supportiveness: What characteristics make a difference? CBE-Life Sciences Education, 20(2), ar29. https://doi.org/10.1187/cbe.20-10-0238

Shortlidge, E. E., Bangera, G., \& Brownell, S. E. (2016). Faculty perspectives on developing and teaching course-based undergraduate research experiences. BioScience, 66(1), 54-62. https://doi.org/10.1093/biosci/biv167

Shortlidge, E. E., Bangera, G., \& Brownell, S. E. (2017). Each to their own CURE: Faculty who teach course-based undergraduate research experiences report why you too should teach a CURE. Journal of Microbiology \& Biology Education, 18(2). https://doi.org/10.1128/jmbe.v18i2.1260

Shortlidge, E. E., \& Eddy, S. L. (2018). The trade-off between graduate student research and teaching: A myth? PLOS ONE, 13(6), e0199576.

Smith, C. R., \& Delgado, C. (2021). Developing a model of graduate teaching assistant teacher efficacy: How do high and low teacher efficacy teaching assistants compare? CBE-Life Sciences Education, 20(1), ar2. https:// doi.org/10.1187/cbe.20-05-0096

Sundberg, M. D., Armstrong, J. E., \& Wischusen, E. W. (2005). A reappraisal of the status of introductory biology laboratory education in US colleges $\&$ universities. American Biology Teacher, 67(9), 525-529.

Watts, S., \& Stenner, P. (2012). Doing Q methodological research: Theory, method \& interpretation. Thousand Oaks, CA: Sage. 
Wheeler, L., Chiu, J., Maeng, J., \& Bell, R. (2018). An exploratory study of teaching assistants' motivation for inquiry-based teaching in an undergraduate laboratory context. Chemistry Education Research and Practice, 20, 53-67. https://doi.org/10.1039/ C8RP00157J
Wigfield, A., \& Eccles, J. S. (2000). Expectancy-value theory of achievement motivation. Contemporary Educational Psychology, 25(1), 68-81. https://doi.org/10.1006/ceps.1999.1015

Yin, R. K. (2017). Case study research and applications: Design and methods Thousand Oaks, CA: Sage. 